\title{
A educación ao aire libre nunha perspectiva histórica
}

\begin{abstract}
«Todas las enseñanzas, deben darse con preferencia al aire libre, forma perfectamente aplicable, en muchas ocasiones, aun a aquellas que parecen más sedentarias e inseparables de la clase cubierta y cerrada».
\end{abstract}

Francisco Giner de los Ríos. Campos escolares. 1884.

O aire libre e a educación en espazos naturais é unha constante na educación contemporánea desde que Rousseau percorreu as sendas dos Alpes e concluíu que camiñar e gozar co que ofrecía cada día a ruta era o que facía feliz a Emilio. Desde que xurdiu a afección ao alpinismo, a percorrer as montañas e os bosques afastándose das contornas urbanas, a natureza comezou a deixar de ser un lugar terrible que desde a Antigüidade semellaba o inicio do descensus ad inferos, ben cruzando o bosque de Perséfone cara ao Hades ou asasinando ao gardián do bosque dos cedros como fixo Gilgamesh e o seu amigo Endikú. O século XVIII descubriu á Humanidade o valor da natureza onde, como dicía Alexander Von Humboldt, estaba a liberdade. O interese pola natureza e os desafíos que ofrecía para conformar un mundo interior de valores tivo tanta intensidade que ningún ilustrado deixou de ler Robinson Crusoe. Escalar montañas e cruzar bosques deixou de ser unha maldición que conducía a lugares de espanto para descubrir os retos que crearon novos modelos de educación, afastados das aulas. Os testemuños que nos deixou Rodolphe Töpffer dos primeiros alpinistas e o seu valioso Les voyages en zigzag (1836) descobren un cambio de mentalidade que trata con humor e pedagoxía nunhas imaxes que describen con gran fidelidade unha época.

Desde cando xurdiu a idea dunha natureza educadora? O descubrimento do pracer de viaxar e desprazarse camiñando provocou a expansión do espírito Wanderlust. Educarse deixou de ser unicamente unha acción reservada aos espazos pechados e imbuída pola emulación aos mestres para apelar ao coidado corporal, a saúde física e anímica, a experimentación de aprendizaxes ao aire libre, a sentirse dono de si mesmo/a e deixar de ser súbdito. Kant consideraba a natureza unha potencia que non ten ningún imperio sobre nós porque é dinamicamente sublime e cara a ela mostramos admiración e asombro: permítenos experimentar «unha satisfacción vivificante». Kant, Schiller e Goethe están na raíz do espírito romántico da natureza como un todo inabarcable que esperta a imaxinación e que ordena as representacións sobre o mundo, construíndo a Weltanschauung en cada persoa. 
Sen chegar ás aplicacións que outros pensadores posteriores á llustración realizaron sobre as bondades educadoras do aire libre, hai unha liña que pasa por Pestalozzi e Fröbel e colle de cheo en España a Francisco Giner e a Institución Libre de Enseñanza; e noutros países a educadores tan emblemáticos como Walter Bion en Suíza, Patrick Geddes en Escocia, Kurt Hahn na Alemaña, ou Robert Baden Powell no Reino Unido. Pero foi en Berlín, a principios do século XX, cando se creou a primeira Waldschule en Charlottenbourg en 1903, iniciando un movemento que axiña se trasladou a outros países, con creacións tan singulares como o Pädagogium de Frewaldan en Austria, ou as escolas de Glarisegg e de Gruman en Suíza. A idea da escola do bosque chegou decontado a España, grazas ao empeño de Domingo Barnés, ao crearse a primeira en Montjuic, baixo a dirección de Rosa Sensat, en 1914; para máis tarde, en 1918, abrirse na Dehesa de la Villa en Madrid, a segunda escola do bosque que dirixiu Flora Mateo da Torre.

Convén sinalar, no entanto, que a educación ao aire libre foi un territorio dominado polas asociacións xuvenís de educación non formal durante o primeiro terzo do século XX. As agrupacións escultistas, creadas por Baden Powell en 1907, estendéronse rapidamente aos cinco continentes $\mathrm{E}$, entre outros, o movemento Wanderwögel creou unha conciencia de identidade xuvenil ata entón descoñecida. 011 de outubro de 1913 os seus líderes reuniron catro mil mozos no monte Meissner nun histórico conclave que contou coa presenza de Gustav Wyneken e no que tamén estiveron Paul Natorp, Martin Heidegger e Ludwig Klages, quen pronunciou un discurso, Mens und Erde, no que se referiu á extinción de innumerables especies animais, á destrución dos bosques e á explotación da natureza, nun ton sombrío e seica precedente dalgúns movementos ecoloxistas actuais.

A pesar de que esta corrente educativa foi crecendo durante todo o século XX, o tipo de cultura que se estendeu polas cidades, produciu unha desconexión case completa co medio natural. As persoas vense actualmente impelidas a uns costumes onde as necesidades básicas se resolven sen grandes esforzos: luz, auga, calor, frío, comunicacións con persoas que viven noutras cidades ou países, soluciónanse con rapidez e sen apenas desgaste de enerxía física. Parécenos todo tan habitual que un pequeno apagamento, ou 0 atraso dun autobús, irrítannos porque alteran os nosos plans, e fai aparecer unha realidade que non podemos dominar cos nosos recursos. Se seguimos os fitos marcados na formación regulada e acomodamos ben a conduta externa aos requirimentos da organización económica e dos códigos sancionados legalmente, a civilización e o urbanismo dánnolo case todo feito.

Xa no século XXI esta falta de mobilidade dos corpos agravouse pola difusión e uso constante de dispositivos dixitais, até o punto de que desprazaron non xa aos xogos infantís e á actividade deportiva máis común, senón que mesmo impiden a vida social que crecía ao redor dun televisor. Sen chegar ao extremo da casuística dos hikikomoris, actualmente unha parte da infancia e mocidade pasa os días recluída en espazos pechados, ás veces en soidade. Un modo de vida que analizou con detalle Anders Szczepanski quen se referiu ao «triangular life form» como un escenario formado pola escola, o fogar e 0 centro comercial en que a xente nova consome o seu tempo sen que poidan coñecer 0 
campo aberto e a vida rural porque o cinto verde das cidades foi substituído por zonas comerciais e de entretemento que non só provocan un forte estrago dos espazos naturais de proximidade, senón tamén dilúe e dificulta as relacións humanas. Moitas escolas foron desprazadas cara ás aforas, pero non están máis próximas á natureza, senón illadas da contorna e accesibles unicamente con automóbil. Para chegar a unha contorna verde é frecuente ter que salvar os aneis de autoestradas que encerran a cidade.

Toda esta nova cultura promoveu un modelo de homo sedentarius que escureceu a cultura do homo viator que propuña Rousseau e que os discípulos de Giner defenderon en España coa súa paixón polo excursionismo escolar e os xogos ao aire libre. E así existe actualmente unha preocupación por volver conectar ás novas xeracións coas contornas naturais e sacalas do ensimesmamento que produce o apego ás pantallas. Hoxe as escolas do bosque que apenas tiveron incidencia hai cen anos desenvólvense en correntes educativas cada vez máis densas como a rede do Waldkindergarten na Alemaña ou as Forest School no Reino Unido. Aquí en España temos un movemento aínda moi tenro, pero que xa celebrou os seus primeiros congresos, que se reúne ao redor da asociación EDNA, un espazo de encontro, intercambio de experiencias e consolidación de proxectos educativos na natureza.

Así, na parte monográfica do presente número de Sarmiento recupéranse algunhas institucións, movementos e ideas que se desenvolveron sobre a educación ao aire libre, con traballos moi diferentes pero que presentan achegas novas en temas que necesitaban ser mellor coñecidos. Maria Romeiras Amado fai unha aproximación á historia do Centro Hellen Keller, unha escola privada portuguesa fundada en 1955 que acolle nenas e nenos cegos, usando unha metodoloxía inspirada en Freinet, e que conta cun parque de máis de mil hectáreas para traballar coa natureza. José Ignacio Cruz fai unha comparación entre as actividades ao aire libre do Frente de Juventudes franquista e o escultismo, a través dos Exploradores de España. A súa conclusión é sumamente interesante ao establecer os distintos usos que fai do aire libre unha organización nitidamente fascista e outra democrática cuxa meta era educar unha cidadanía activa e libre. Establece o diferente que resulta levar aos mozos á natureza para apartalos da súa realidade cotiá e adoutrinalos ou desenvolver unha conciencia ambiental cando apenas ninguén daba importancia ás potencialidades educadoras da natureza.

Hai tamén tres artigos que estudan o fenómeno das escolas do bosque desde perspectivas distintas. Ananda Casanova en «Escolas dá floresta: ou modelo de educação infantil ao ar livre na Europa e Espanha» fai un percorrido pola historia deste movemento en Europa e España. O máis interesante da súa achega é que o realiza desde unha óptica americana e reflexiona sobre o momento actual, «no qual vivemos sob as eminentes ameaças à diversidade biológica e cultural, das consequências da urbanização e do emparedamento da infância». Despois, Mirella D'Ascenzo recapitula sobre a orixe e desenvolvemento das escolas do bosque en Italia, ilustrando a que foi a primeira creada nese país, na cidade de Padua, demostrando que o movemento hixiénico open air que as animou ao principio estaba moi estendido en Europa. En terceiro lugar Noelia Díaz e eu mesmo 
achegámonos ao recente movemento das escolas na natureza en España para deternos nos dous exemplos paradigmáticos de Galicia: Nenea e Amadahi. Neste caso quixemos poñer 0 acento na importancia que ten a historia do presente, porque o movemento das escolas na natureza é un fenómeno novo, con importantes diferenzas sobre as escolas do bosque que apareceron no primeiro terzo do século XX, pero que tamén representan unha continuidade sobre esa valiosa herdanza educativa.

Esta parte do monográfico complétase con dous artigos moi diferentes na súa metodoloxía e intencionalidade. Raquel Cutrín, Silvia Basanta e Rubén Navarro presentan unha reflexión sobre tres metodoloxías de traballo estendidas no ámbito dos movementos educativos en relación co medio natural. Por unha banda, o que os anglosaxóns chaman outdoor learning, que non sempre coincide con algúns dos conceptos que viñemos usando aquí, responde á aprendizaxe que se realiza ao aire libre en contornas naturais. Outras metodoloxías con moita incidencia nesta pedagoxía son o traballo cooperativo e a aprendizaxe experiencial. Estudan o marco legal en que estas actividades se realizan en Galicia e conclúen que estas tres correntes non actúan de forma illada, pero que é importante contar con contornas próximas aos centros educativos ás que se poida acceder a miúdo e «que sexa a propia contorna quen favoreza a creatividade, a imaxinación e a curiosidade dos participantes». Inez Pinheiro e Beatriz Fernández, finalmente, penetran na cultura indíxena do Brasil, recuperando o concepto do Bem Viver. Creo que é a primeira vez que se aborda este tema nunha revista española. As cosmovisións que intentan explicarnos para que vivimos, o valor que ten a contorna no que chegamos a ser, o que podemos hoxe aprender dos pobos indíxenas neste sentido, segue sendo un tema certamente atraínte. $\mathrm{O}$ importante da súa achega é que fai un percorrido desde un concepto tradicional dunha cultura primitiva, dos pobos de selva amazónica, á súa adopción por certos segmentos políticos, e sen dúbida educativos, da América do Sur nun tempo recente.

Nos documentos que se centran no tema deste número recupéranse dúas ideas moi dispares pero reveladoras do que a educación ao aire libre representou, e representa, no mundo contemporáneo. Por unha banda, o profesor Antón Costa rescata os primeiros textos escritos por Portela Valladares e Otero Pedrayo en galego para conmemorar o Día da Árbore, que xunto a outro breve de Joaquín Costa foron impresos polo xornal El Pueblo Gallego, en 1927. Pola outra, Lidia Miró achéganos ao concepto de friluftsliv nos países nórdicos e o efecto que produce nos seus seguidores mediante a recuperación dun relato persoal. Define o friluftsliv como unha «arte que conecta o espírito coa natureza, que retorna o noso ser ás súas raíces» e, que «busca a harmonía co que nos rodea, o noso lugar neste mundo». Aproxímanos a unha idea central na educación dos países nórdicos que frecuentemente conforma o nervio da súa vida, dos seus hábitos sociais e valores.

Non queda senón sinalar que Sarmiento neste número reafirma a súa vontade de ser unha revista que combina, nunha conxunción feliz, a cultura ibérica coa cultura latinoamericana; e a hispanidade coa lusofonía. Pero tamén se abre a todas as raíces culturais, aos estratos que conforman a historia da educación en calquera parte do mundo. Non só ten importancia por dar canle a unha lingua minoritaria en cordial convivencia con outras 
máis fortes, senón tamén porque os temas locais, que publicamos nesta revista, se entrelazan con outros máis universais. Formamos o eixe atlántico da península lbérica, pero tamén somos parte dunha civilización con moitas interinfluencias, desde o que nos deixa unha tribo do Amazonas ata o que temos que aprender do estilo de vida dos países máis desenvolvidos. A historia da educación nas contornas naturais ten aínda moitos capítulos inéditos, tanto no ámbito formal como no non formal, que necesitarán abordarse. Nesta ocasión entresacamos algúns exemplos.

Eugenio OTERO URTAZA

(Coordinador do monográfico) 